\title{
Calvarial Reconstruction
}

Arvind Badhey, MD ${ }^{1}$ Sameep Kadakia, MD $^{2}$ Moustafa Mourad, MD ${ }^{2}$ Jared Inman, MD

Yadranko Ducic, $\mathrm{MD}^{2}$

${ }^{1}$ Department of Otolaryngology, New York Eye and Ear Infirmary of Mount Sinai, New York

2 Otolaryngology and Facial Plastic Surgery Associates, Fort Worth, Texas

${ }^{3}$ Department of Otolaryngology, Loma Linda University,

Loma Linda, California

Address for correspondence Yadranko Ducic, MD, Otolaryngology and Facial Plastic Surgery Associates, 923 Pennsylvania Ave, Fort Worth, TX 76104 (e-mail: yducic@sbcglobal.net).

Semin Plast Surg 2017;31:222-226.
Abstract
Keywords
- calvarium reconstruction
- cranioplasty
- hydroxyapatite
- autologous cranioplasty
- methyl methacrylate
- synthetic cranioplasty
Calvarial reconstruction is a challenge to reconstructive surgeons, especially consider- ing protection of intracranial contents. In recent years, the advent of multiple reconstructive materials adds tools to the surgical armamentarium. Options include autologous split calvarial and rib grafts and alloplastic materials such as titanium mesh, methyl methacrylate, calcium hydroxyapatite, and polyetheretherketone. The most important aspect of cranial reconstruction still lies in finding the most aesthetic, safe, and reliable means of filling a defect.

Approaching the reconstruction of calvarial defects requires multiple rungs from the reconstructive ladder. In turn, each case is uniquely challenging for the reconstructive surgeon. The simplest approach requires a foundational knowledge of the tools within the reconstructive arsenal and openness to innovation. Any bony defect, in this case calvarium, adds complexity to reconstruction by dealing with structural support, contour, and function. ${ }^{1}$ The advancement of calvarium reconstructive ranges from well-known surgical techniques, molded materials, and sculpted implants. ${ }^{2-6}$ All of which have gone through multiple iterations as science catches up to practice. Thus, there has yet to be a clear consensus on what option is best. ${ }^{7,8}$

The typical reconstructive focus encompasses cosmesis and support. In calvarial reconstruction added aspects of protecting craniodural structures, recreation of normal CSF pressure and blood flow, and donor-site morbidity complicate preoperative planning. ${ }^{9}$

In this review, we will discuss the current scientific and clinical progress of calvarial reconstruction. This article aims to present the typical management considerations, the newest innovative materials, and the specialized operative techniques used today.

\section{Preoperative Planning}

Two tenets guide calvarial reconstruction: re-establishing contour and protecting cranial contents. To begin this process, a fundamental knowledge of calvaria anatomy and the etiology of defects are important. The calvaria consist of three layers: an outer table of cortical bone, diploic medullary space of cancellous bone, and an inner table of thinner cortical bone. The overlying soft tissues of the scalp consist of five layers: skin (contains hair follicles and sebaceous glands), subcutaneous tissue (contains the scalp vasculature), galea aponeurosis (dense fibrous layer contiguous with the fascia of the frontalis muscle and the temporoparietal fascia), loose areolar tissue (layer which allows superficial layers to shift relative to the pericranium), and the pericranium (the periosteum blood supplying layer of the cranial bones). ${ }^{10}$ - Fig. 1 is an illustration of the anatomy previously described. Defects within each of these layers can result in various forms of trauma, tumor resection, or osteoradionecrosis. ${ }^{11,12}$

In addition, a surgeon must be aware and attempt to best manage medical comorbidities. A smoking history, uncontrolled diabetes, and local infections are some aspects that significantly affect wound healing and in turn successful reconstruction. ${ }^{13}$
Issue Theme Skull Base Reconstruction; Guest Editor: Yadranko Ducic, MD

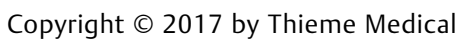
Publishers, Inc., 333 Seventh Avenue, New York, NY 10001, USA. Tel: +1(212) 584-4662. ISSN 1535-2188. 


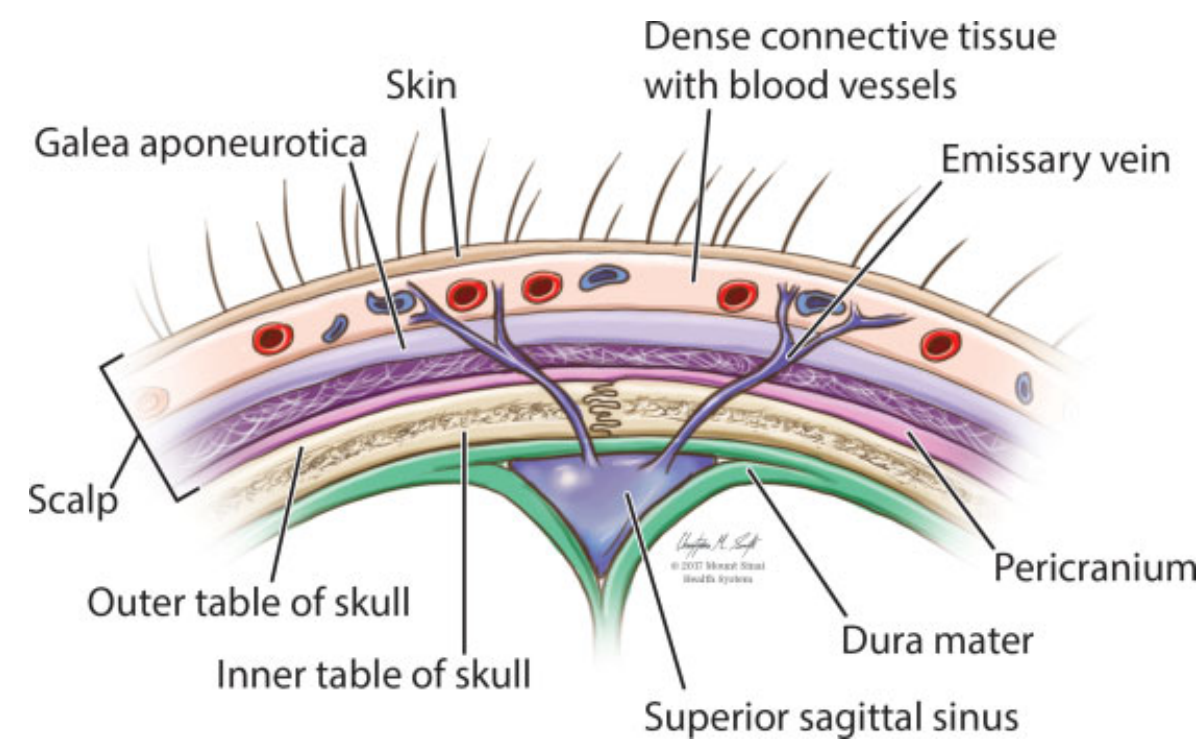

Fig. 1 Anatomical illustration of the scalp and calvarium (Artwork courtesy of Christopher M. Smith from the Mount Sinai Health System).

Importantly, recreating the separation between cranial contents and external elements has been shown to improve neurologic outcomes and aid in cerebral flow and CSF hemodynamics. $^{14,15}$

Finally, without adequate reconstruction patients can suffer from a host of significant complications, psychologic distress, headaches, dizziness, and fatigue. ${ }^{16}$

\section{Materials}

Calvarial reconstruction dates back hundreds of years, with materials ranging from precious metals and cork to coral and coconuts. ${ }^{17-19}$ Modern options range from autografts to computer mapped implantables, each of which must be tailored to the specific patient. The ideal material can protect intracranial contents has good contour, is malleable, lightweight, and can be easily integrated into native bone. It must also be resistant to infection, prevent a robust inflammatory response, be isothermic and not conduct heat, and not be prone to biologic breakdown. ${ }^{20}$

\section{Autologous Bone}

Autologous bone is an autograft that works best by integrating into the native bone with high potential for growth. This portends to a lower chance of graft loss because infected bone can be salvaged with debridement. Although history has shown multiple harvest sites, including iliac crest and tibia, the modern harvest sites include calvarial bone and split-rib grafts. ${ }^{21}$

Use of the external table of the cranium with its overlying periosteum was described as early as 1900 , and as time has passed, it has remained relevant as an effective means of reconstruction in the modern era. ${ }^{21-23} \mathrm{~A}$ calvarial graft is the most natural material for reconstruction. It can easily be harvested from the local field-commonly from the parietal skull laterally, where bone is the thickest and a safe distance from the sagittal sinus. A fresh autologous graft provides the ideal structural and histocompatibility properties for osteointegration with a low incidence of infections. ${ }^{24}$ The main risks associated with calvarial grafts to consider are limited size due to the original defect and risk of violating the inner table or dura during harvest.

The use of split-rib grafts was also introduced in the early 1900 s. $^{25}$ It can be effective for larger defects, and for cosmetically obvious areas such as a frontal defect. During harvest, removing more than two adjacent ribs can cause chest wall instability; alternating ribs can minimize this risk and contour deformities. Dissection is performed subperiosteally to protect the underlying pleura. Grafts are then bent and placed in a plank fashion within the defect, with gaps filled with bone chips or paste. ${ }^{13}$ Concerns raised regarding splitrib grafts include bone movement-solved by rigid fixation with screws and plates-and long-term irregular contour. In the senior author's experience, split-rib is most commonly used and effective in pediatric patients. In addition, it has been found that iliac bone is reliable, with favorable curvature, and good long-term results.

All types of autologous grafts run the risk of bone reabsorption, infection, donor-site morbidity and at times poor cosmesis. Interestingly, recent advances in harvesting calvarium from tissue-expander hyperostosis provide a viable alternative to generating bone graft without major donor-site morbidity. ${ }^{26,27}$ Ultimately, if these risks can be avoided, autologous bone meets all the requirements of an ideal reconstructive tool.

\section{Allografts and Xenografts}

Initial calvarial reconstruction included animal and cadaveric tissue. Although canine bones and animal horns were common place for the time, the improved outcomes of autografts and bone substitutes made these types of reconstructions obsolete. ${ }^{28,29}$ Similarly, cadaveric cartilage fell out of favor as it was found to insufficiently calcify. ${ }^{30}$ 


\section{Synthetics}

As defect size places limits on the usable autologous bone, room is made for synthetic bone substitutes. These materials have become popular as they prevent donor-site morbidity, maintain strength over time without reabsorption, and are malleable enough to be contoured. ${ }^{31}$

Multiple materials have come in and out of favor, with none established as superior. The most common include titanium mesh, methyl methacrylate (MMA), hydroxyapatite, and polyetheretherketone (PEEK)-each with advantages and disadvantages.

\section{Titanium Mesh}

Titanium mesh has multiple uses, either as a long scaffold for reconstruction or as a framework with other materials creating a smooth fused implant. Titanium, is a noncorrosive metal, with limited inflammatory reaction and a minimal risk of infection. ${ }^{32-34}$ It also has the added benefit of covering large defects, with similar contouring preoperatively. ${ }^{35}$ The use of mesh plates has drastically increased with the advent of threedimensional computed tomography (3D CT) prefabricated implants. Using customized implants crafted with light-sensitive resin and CT data, stereolithographic models with multiple synthetic bases can be made. ${ }^{14,36}$ - Figs. 2 and $\mathbf{3}$ show an illustration of a calvarial defect followed by reconstruction with a smooth titanium amalgam plate.

Though these customized implants can be fairly costly, patients have reported high satisfaction with both cosmetic results and quality of life in a long-term follow-up study. ${ }^{37}$ In addition, titanium mesh is a thermoconductor and depending on mixed metal concentrations can cause scatter artifacts on routine imaging. Finally, over years of implantation, the overlying skin can be thinned with eventual exposure of the mesh. ${ }^{38}$

\section{Methyl Methacrylate}

Methyl methacrylate (MMA) is a synthetic polymer of acrylic acid, able to handle levels of stress similar to that of native bone.

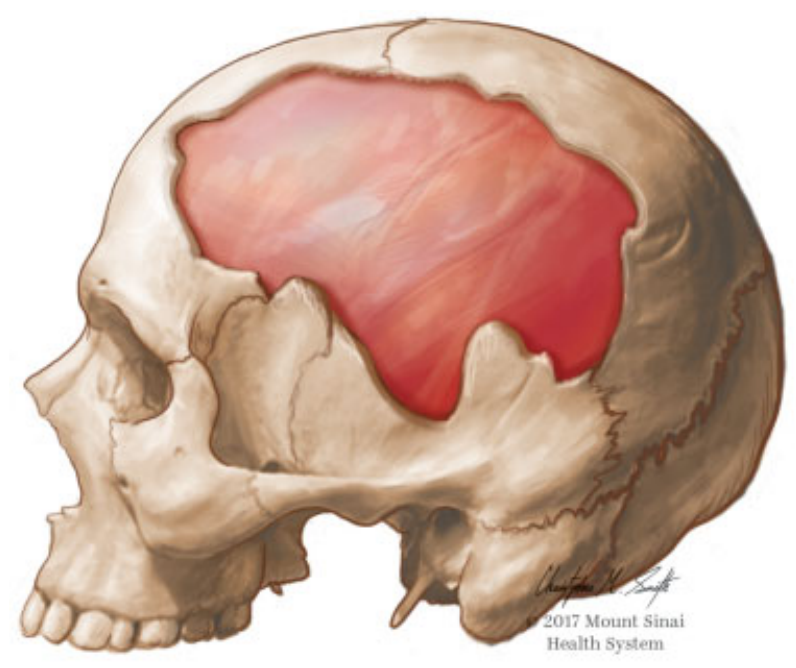

Fig. 2 Postsurgical defect in the calvarium showing underlying exposed dura and brain (Artwork courtesy of Christopher M. Smith from the Mount Sinai Health System).

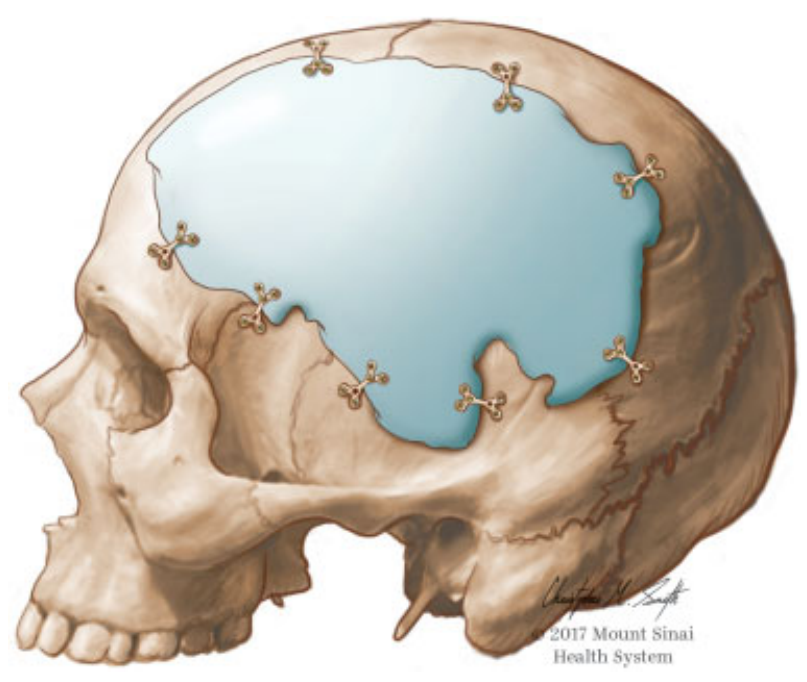

Fig. 3 Reconstruction of the calvarial defect from - Fig. 2 with a smooth titanium amalgam (Artwork courtesy of Christopher M. Smith from the Mount Sinai Health System).

When mixed, it starts as a malleable paste, which when cooled evenly shapes to fit a defect. ${ }^{39}$ It is a stable inert substance with minimal local reaction to the meninges. ${ }^{40}$ More recently, it has been typically combined with titanium mesh as a structural lattice-this reduces the risk of fracture of pure MMA. ${ }^{41,42}$

Methyl methacrylate is a polymeric powder, which when mixed into a paste causes an exothermic reaction. This can cause dangerous burns to local tissues, and during placement, the implant must constantly be irrigated with cool saline. MMA also has a risk of infection in $5 \%$ of cases, with an added risk of fracture due to poor native bone ingrowth. The implant itself prevents proper local growth, and is thus commonly avoided in pediatric populations. ${ }^{43,44}$ In an attempt to avoid some of these pitfalls, premade MMA models have become a regular occurrence. ${ }^{45}$

\section{Hydroxyapatite}

Hydroxyapatite is a calcium phosphate with a composition similar to mineral phase bone, but can be mass-produced as a ceramic. ${ }^{46}$ Similar to MMA, hydroxyapatite can be combined with titanium mesh to create a fused reconstruction. However, unlike MMA the hardening process is isothermic and it allows for expansion with growing calvarium-with safe use in pediatric patients. With a minimal inflammatory reaction, hydroxyapatite premade prostheses with pores can be constructed to ensure bone ingrowth. ${ }^{21}$ Hydroxyapatite should be avoided from contact with the frontal sinus, placement near a coronal incision, or preceding postoperative radiation, as there is an increased risk of infection. ${ }^{47}$

A disadvantage of hydroxyapatite is a lack of lamellar organization; a low tensile strength implant is prone to fragmenting over time. ${ }^{43,48}$ As a result, it is commonly used for smaller calvarial defects. ${ }^{49,50}$

\section{Polyetheretherketone}

Polyetheretherketone (PEEK) is a chemically inert semicrystalline powder. Implants made of PEEK have strength matching 
that of cortical bone. ${ }^{51}$ This strength along with seamless 3D printing of customized implants has made PEEK a popular option. Its advantage lies in minimal imaging artifact, being nonmagnetic, lightweight, and an inert nonconductor. Unfortunately, the composition of these implants does not provide fodder for osteointegration. ${ }^{52}$

\section{Preformed Implants}

The introduction of 3D CT and its use to create anatomical models revolutionized calvarial reconstruction. Using 3D printing, a patient's natural anatomy can be simply recreated. ${ }^{6}$ Prior to prefabricated modeling, standardized mass produced models were contoured based on the eye and without ideal instruments. The change to patient-specific implants, created molds tailored to promoting normal bony ingrowth and healing. ${ }^{53}$ It was initially thought that these prefabricated implants were limited by the size of a defect. Yet recent studies have shown effectiveness with large scale plates. ${ }^{54}$ Now multiple commercial leaders are pioneering more advancements in ways of automated construction and simple implant models.

\section{Conclusion}

Options for calvarial reconstruction include autologous split calvarial and rib grafts and alloplastic materials such as titanium mesh, MMA, calcium hydroxyapatite, and PEEK. Successful reconstruction of the calvaria and scalp may require multiple "rungs" on the reconstructive ladder. The key to effective calvarial reconstruction is choosing the ideal material for the defect.

\section{Conflict of Interest}

None.

\section{Acknowledgment}

We would like to thank Christopher Smith from the Mount Sinai Health System for producing high-quality images for this article.

\section{References}

1 Ioannides C, Fossion E, McGrouther AD. Reconstruction for large defects of the scalp and cranium. J Craniomaxillofac Surg 1999;27 (03):145-152

2 Warren SM, Fong KD, Chen CM, et al. Tools and techniques for craniofacial tissue engineering. Tissue Eng 2003;9(02):187-200

3 Habal MB, Pietrzak WS. Key points in the fixation of the craniofacial skeleton with absorbable biomaterial. J Craniofac Surg 1999;10(06):491-499

4 Ono I, Tateshita T, Satou M, Sasaki T, Matsumoto M, Kodama N. Treatment of large complex cranial bone defects by using hydroxyapatite ceramic implants. Plast Reconstr Surg 1999;104(02): 339-349

5 Eppley BL, Kilgo M, Coleman JJ III. Cranial reconstruction with computer-generated hard-tissue replacement patient-matched implants: indications, surgical technique, and long-term followup. Plast Reconstr Surg 2002;109(03):864-871

6 D'Urso PS, Earwaker WJ, Barker TM, et al. Custom cranioplasty using stereolithography and acrylic. Br J Plast Surg 2000;53(03): 200-204
7 Wiggins A, Austerberry R, Morrison D, Ho KM, Honeybul S. Cranioplasty with custom-made titanium plates-14 years experience. Neurosurgery 2013;72(02):248-256, discussion 256

8 Harris DA, Fong AJ, Buchanan EP, Monson L, Khechoyan D, Lam S. History of synthetic materials in alloplastic cranioplasty. Neurosurg Focus 2014;36(04):E20

9 Aydin S, Kucukyuruk B, Abuzayed B, Aydin S, Sanus GZ. Cranioplasty: review of materials and techniques. J Neurosci Rural Pract 2011;2(02):162-167

10 Thomaidis V. Cutaneous Flaps in Head and Neck Reconstruction. Anatomy to Surgery. Heidelberg, Germany: Springer; 2014

11 Tolhurst DE, Carstens MH, Greco RJ, Hurwitz DJ. The surgical anatomy of the scalp. Plast Reconstr Surg 1991;87(04):603-612, discussion 613-614

12 Hoffman JF. Management of scalp defects. Otolaryngol Clin North Am 2001;34(03):571-582

13 Lin SJ, Hanasono MM, Skoracki RJ. Scalp and calvarial reconstruction. Semin Plast Surg 2008;22(04):281-293

14 Song J, Liu M, Mo X, Du H, Huang H, Xu GZ. Beneficial impact of early cranioplasty in patients with decompressive craniectomy: evidence from transcranial Doppler ultrasonography. Acta Neurochir (Wien) 2014;156(01):193-198

15 Honeybul S, Janzen C, Kruger K, Ho KM. The impact of cranioplasty on neurological function. Br J Neurosurg 2013;27(05):636-641

16 Grant FC, Norcross NC. Repair of cranial defects by cranioplasty. Ann Surg 1939;110(04):488-512

17 Chim H, Schantz JT. New frontiers in calvarial reconstruction: integrating computer-assisted design and tissue engineering in cranioplasty. Plast Reconstr Surg 2005;116(06):1726-1741

18 Courville CB. Cranioplasty in prehistoric times. Bull Los Angel Neuro Soc 1959;24(01):1-8

19 Ellis W. Polynesian Researches. Vol. III. London: Fisher, Son \& Jackson; 1836:34

20 Koksal V, Kayaci S, Bedir R. Split rib cranioplasty for frontal osteoma: a case report and review of the literature. Iran Red Crescent Med J 2016;18(07):e29541

21 Zanotti B, Zingaretti N, Verlicchi A, Robiony M, Alfieri A, Parodi PC. Cranioplasty: review of materials. J Craniofac Surg 2016;27(08): 2061-2072

22 Mueller W. Zur frage der temporaren schadelresektion an stelle der trepanation. Zentralbl Chir 1890;17:65

23 Backdahl EO, Eriksson GX. Paper presented at: Meeting della Società Scandinava di Chirurgia Plastica. Stockholm, Sweden: 1966

24 Artico M, Ferrante L, Pastore FS, et al. Bone autografting of the calvaria and craniofacial skeleton: historical background, surgical results in a series of 15 patients, and review of the literature. Surg Neurol 2003;60(01):71-79

25 Açikgöz B, Özcan OE, Erbengi A, Bertan V, Ruacan S, Açikgöz HG. Histopathologic and microdensitometric analysis of craniotomy bone flaps preserved between abdominal fat and muscle. Surg Neurol 1986;26(06):557-561

26 Hadad I, Meara JG, Rogers-Vizena CR. A novel local autologous bone graft donor site after scalp tissue expansion in aplasia cutis congenita. J Craniofac Surg 2016;27(04):904-907

27 Greene AK, Mulliken JB, Proctor MR, Rogers GF. Pediatric cranioplasty using particulate calvarial bone graft. Plast Reconstr Surg 2008;122(02):563-571

28 Haeseker B. Van Meekeren and his account of the transplant of bone from a dog into the skull of a soldier. Plast Reconstr Surg 1991;88(01):173-174

29 Durand JL, Renier D, Marchac D. [The history of cranioplasty]. Ann Chir Plast Esthet 1997;42(01):75-83

30 Woolf JI, Walker AE. Cranioplasty: collective review. Int Abstr Surg 1945;81:1-23

31 Goldstein JA, Paliga JT, Bartlett SP. Cranioplasty: indications and advances. Curr Opin Otolaryngol Head Neck Surg 2013;21(04): 400-409 
32 Matsuno A, Tanaka H, Iwamuro H, et al. Analyses of the factors influencing bone graft infection after delayed cranioplasty. Acta Neurochir (Wien) 2006;148(05):535-540, discussion 540

33 Shah AM, Jung H, Skirboll S. Materials used in cranioplasty: a history and analysis. Neurosurg Focus 2014;36(04):E19

34 Marbacher S, Andres RH, Fathi AR, Fandino J. Primary reconstruction of open depressed skull fractures with titanium mesh. J Craniofac Surg 2008;19(02):490-495

35 Eufinger $\mathrm{H}$, Wehmoller $\mathrm{M}$, Wethe $\mathrm{S}$, Machtens $\mathrm{E}$. Individual prefabricated titanium implants for cranioplasty. Int J Oral Maxillofac Surg 1999;28:172

36 Winder J, Cooke RS, Gray J, Fannin T, Fegan T. Medical rapid prototyping and 3D CT in the manufacture of custom made cranial titanium plates. J Med Eng Technol 1999;23(01):26-28

37 Cabraja M, Klein M, Lehmann TN. Long-term results following titanium cranioplasty of large skull defects. Neurosurg Focus 2009;26(06):E10

38 Singh M, Ricci JA, Dunn IF, Caterson EJ. Alloderm covering over titanium cranioplasty may minimize contour deformities in the frontal bone position. J Craniofac Surg 2016;27(05): 1292-1294

39 Marchac D, Greensmith A. Long-term experience with methylmethacrylate cranioplasty in craniofacial surgery. J Plast Reconstr Aesthet Surg 2008;61(07):744-752, discussion 753

40 Henry HM, Guerrero C, Moody RA. Cerebrospinal fluid fistula from fractured acrylic cranioplasty plate. Case report. J Neurosurg 1976;45(02):227-228

41 Galicich JH, Hovind KH. Stainless steel mesh-acrylic cranioplasty. Technical note. J Neurosurg 1967;27(04):376-378

42 Chiarini L, Figurelli S, Pollastri G, et al. Cranioplasty using acrylic material: a new technical procedure. J Craniomaxillofac Surg 2004;32(01):5-9

43 Rubin JP, Yaremchuk MJ. Complications and toxicities of implantable biomaterials used in facial reconstructive and aesthetic surgery: a comprehensive review of the literature. Plast Reconstr Surg 1997;100(05):1336-1353
44 Blum KS, Schneider SJ, Rosenthal AD. Methyl methacrylate cranioplasty in children: long-term results. Pediatr Neurosurg 1997; 26(01):33-35

45 Turgut G, Özkaya Ö, Kayali MU. Computer-aided design and manufacture and rapid prototyped polymethylmethacrylate reconstruction. J Craniofac Surg 2012;23(03):770-773

46 Sanan A, Haines SJ. Repairing holes in the head: a history of cranioplasty. Neurosurgery 1997;40(03):588-603

47 Verret DJ, Ducic Y, Oxford L, Smith J. Hydroxyapatite cement in craniofacial reconstruction. Otolaryngol Head Neck Surg 2005; 133(06):897-899

48 Frassanito P, De Bonis P, Mattogno PP, et al. The fate of a macroporous hydroxyapatite cranioplasty four years after implantation: macroscopical and microscopical findings in a case of recurrent atypical meningioma. Clin Neurol Neurosurg 2013; 115(08):1496-1498

49 Miyake H, Ohta T, Tanaka H. A new technique for cranioplasty with L-shaped titanium plates and combination ceramic implants composed of hydroxyapatite and tricalcium phosphate (Ceratite). Neurosurgery 2000;46(02):414-418

50 Gilardino MS, Cabiling DS, Bartlett SP. Long-term follow-up experience with carbonated calcium phosphate cement (Norian) for cranioplasty in children and adults. Plast Reconstr Surg 2009; 123(03):983-994

51 Lethaus B, Safi Y, ter Laak-Poort M, et al. Cranioplasty with customized titanium and PEEK implants in a mechanical stress model. J Neurotrauma 2012;29(06):1077-1083

52 Wang JC, Wei L, Xu J, Liu JF, Gui L. Clinical outcome of cranioplasty with high-density porous polyethylene. J Craniofac Surg 2012;23 (05):1404-1406

53 Cooke MN, Fisher JP, Dean D, Rimnac C, Mikos AG. Use of stereolithography to manufacture critical-sized 3D biodegradable scaffolds for bone ingrowth. J Biomed Mater Res B Appl Biomater 2003;64(02):65-69

54 Dean D, Min KJ, Bond A. Computer aided design of large-format prefabricated cranial plates. J Craniofac Surg 2003;14(06):819-832 